\title{
ENTRE «BORN DIGITAL»Y HERENCIA LITERARIA: EL DIÁLOGO ENTRE FORMATOS LITERARIOS Y TECNOLOGÍA DIGITAL EN LA POÉTICA ELECTRÓNICA HISPANOAMERICANA
}

Claire TAYLOR

University of Liverpool

c.l.taylor@liv.ac.uk

$\mathrm{E}$ n este artículo propongo analizar la poética electrónica en un contexto latinoamericano y dentro de una tradición literaria hispánica. El artículo parte de la hipótesis de que los nuevos géneros ciberliterarios existen en constante diálogo con una tradición arraigada de experimentación literaria en América Latina: varios de los géneros ciberliterarios emergentes, tales como la poesía-twitter, la novela-hipertexto, o el blog literario, no se mueven dentro de un espacio libre de referentes culturales. Más bien, dialogan con movimientos literarios precursores como la poesía concretista, los caligramas, el testimonio, la crónica, y muchos otros. Tal es el caso, por ejemplo, de la obra de la autora mexicana Noemí Guzik Glantz, cuyos relatos-blog toman prestados elementos de los géneros literarios establecidos, tales como la crónica y el diario íntimo, o de los aforismos-blog del autor latino Eduardo Navas, que dialogan con el género del manual de conducta y el libro de aforismos $^{1}$. En todos estos ejemplos, lo que vemos es, por un lado, el uso experimental de las nuevas tecnologías digitales para crear nuevas estructuras expresivas y empujar las fronteras de lo posible, combinado, por otro lado, con un diálogo continuo y profundo con los géneros literarios impresos y una larga tradición literaria en el mundo hispánico.

Igual que en los géneros ya mencionados, este doble impulso —entre novedad digital y herencia literaria- se observa en la poética digital, donde encontramos múltiples ejemplos de las complejas negociaciones entre tecnología y literatura. Mi propósito en este artículo es, por lo tanto, hacer un análisis comparativo de dos obras poéticas latinoamericanas, para tratar de identificar las diferentes estrategias de negociación y diálogo llevadas a cabo por ambas. Las dos obras pertenecen a autores o co-autores argentinos, pero, como veremos a continuación, las estrategias utilizadas son distintas: la primera efectúa un proyecto de re-activación de la poesía impresa por medio de las tecnologías

${ }^{1}$ Hago un análisis Glantz en Taylor (2007) y de los aforismos-blog de Navas en Taylor (2013). 
digitales; en la segunda, por el contrario, la generación misma de la poesía, y su ejecución por el lector, existen gracias a la tecnología. Es por eso que, en el título de este artículo, hago referencia, de manera irónica, a la noción de «born digital»; en efecto, como veremos más adelante, la poesía construida a base de tecnología, la que nace de la tecnología — la poesía «born digital»— tiene, en realidad, raíces profundas que se extienden hacia las tradiciones literarias pre-digitales. Lo que vemos en estas dos obras, entonces, son las negociaciones de las posibilidades de las nuevas tecnologías digitales, junto con la negociación de los géneros literarios establecidos.

El primer ejemplo es la obra colaborativa, Women: Memory of Repression in Argentina, de 2003, basada en una exposición que lleva el mismo nombre. La exposición fue dirigida por la artista argentina Raquel Partnoy, y la interfaz de aquella fue creada por el artista alemán, Wilfried Agrícola de Cologne, en colaboración con Partnoy. Como veremos, esta interfaz funciona como obra de arte, como interfaz poética en sí, y si examinamos sus estrategias, vemos cómo demuestran la dinámica de la memoria y la resistencia, por un lado, y, por otro, resaltan el papel de la tecnología, así como la importancia del lugar físico en establecer una memoria resistente.

La interfaz ofrece al espectador-usuario una combinación compleja de código informático, memoria, y lugar físico, así que, aun antes de contemplar las diferentes obras de la exposición, la interfaz nos hace un juego poético, estableciendo los temas centrales de dicha exposición. Al abrir la página, se va cargando una pantalla de gris oscuro en medio de la cual aparece un cursor titilante; luego, paulatinamente, un texto brota en la pantalla en letra morada, escrito en fuente Courier. El texto surge letra por letra, y el cursor se mueve de manera lentísima; por fin, podemos distinguir la frase completa, «running to Buenos Aires -- >».

Lo que tenemos aquí es un truco poético-digital que nos recuerda, de manera deliberada, una época pasada de computación y del net.art tempranero. Hay varios elementos en esta poesía textualvisual que imitan el código informático y que hacen referencia a tecnologías anticuadas. El cursor titilante, por ejemplo, es una referencia a los terminales pre-visuales, que usaban solo texto, de los años setenta y ochenta. Igualmente, la manera en que aparece el texto, de una lentitud marcada y deliberada, también trae a mente épocas pasadas en términos informáticos, en las que los programas se demoraban considerablemente en cargar. De igual manera, el uso de Courier — una letra diseñada en 1955 y creada específicamente para imitar el texto de una máquina de escribir - nos lleva a una época antigua en términos informáticos. Por un lado, la letra Courier en sí, por su imitación de la máquina de escribir, y por su nombre (el cual remite al correo, la forma pre-digital de mandar información), nos lleva a las formas pre-digitales de comunicación representadas por la máquina de escribir y el correo. Por otro lado, la letra Courier es la que más frecuentemente se ha empleado en el arte-ASCII, un género artístico en el que se creaban imágenes a partir de letras, números y símbolos, y que empezó en los años sesenta, antes de la existencia de las interfaces visuales. Como la letra Courier es de mono-espacio, todos los caracteres son de igual tamaño, y por eso era una de las letras preferidas de los artistas ASCII ${ }^{2}$. La letra

\footnotetext{
${ }^{2}$ Aunque el arte-ASCII se practicaba principalmente en los 60 y 70, varios net artistas recientes han vuelto a esta forma artística, y han jugado con sus normas; ver, por ejemplo, las obras de JODI y Vuk Cosic. Asimismo, es interesante notar
} 
Courier, entonces, recuerda este género artístico digital tempranero, y, como lo describe Liu, tomando prestadas las palabras de Lunenfeld, el uso de los caracteres ASCII está «tinged by nostalgia» [impregnado de nostalgia] y dan la impresión de un «retro-styling» [estilo retro], dado que simulan las pantallas viejas y los sistemas viejos basados en DOS (2004: 349). Además de eso, el uso de lo que, a primera vista, son elementos de código informático — los símbolos «-»y «〉» — recuerda las técnicas de net.artistas tempranos como $\mathrm{JODI}^{3}$, mientras que la frase «running», de forma lúdica, implica estamos esperando mientras corre el software.

Todos estos elementos combinan para crear una interfaz deliberadamente anticuada en la que resaltan el código informático y las estructuras de los medios digitales como componentes artísticos. De esta manera, la pantalla principal sitúa esta exposición en el contexto del uso resistente del llamado «low tech», es decir, el uso deliberado de tecnologías anticuadas para resistir a las grandes corporaciones informáticas. Esta táctica se ve reflejada en la obra de varios artistas electrónicos latinoamericanos; artistas como el uruguayo Brian Mackern, cuyo Netart latino database (2000-2005) utiliza bosquejos ASCII para dibujar el continente americano, la colombiana Martha Patricia Niño, que frecuentemente se sirve del texto verde neón, imitando las pantallas pre-visuales, en sus obras ${ }^{4}$, o los artistas Coco Fusco y Ricardo Domínguez, que presentaron su Turista Fronterizo (2005) en un empaque anticuado de PacMan y emplearon, en distintas formas, el low-tech como forma de expresión cultural resistente.

Entonces, podemos interpretar esta obra dentro de una tradición latinoamericana del uso resistente del low-tech: una forma de negar las normas de la tecnología ultra-moderna, y de buscar originalidad en lo tecnológicamente anticuado y fuera de moda. Pero, al mismo tiempo, estas referencias ubican la exposición dentro de un contexto histórico concreto. Primero, el uso del código informático fingido en «-- >» es un truco visual que trata no de imitar un comando informático sino de crear la imagen de una flecha en la pantalla, al estilo arte-ASCII. Esta flecha, combinada con las palabras «Buenos Aires», da la impresión de un viaje hacia un lugar concreto, y enfatiza que las obras que observaremos nos transportarán a Buenos Aires. Segundo, las referencias implícitas a los años setenta y ochenta que producen la letra anticuada, el cursor titilante, y la lentitud del software, dan una perspectiva política a la exposición. Porque los años setenta y ochenta en Argentina no remiten a un simple «retro-styling» nostálgico, ni a una nostalgia lúdica por el net.art al estilo JODI, por ejemplo; son los años en los que Argentina estaba en plena dictadura militar, viviendo la represión más aterradora de su historia. El estilo retro aquí, entonces, no se emplea para recordar una época utópica de hackismo, sino para llevarnos a la época de la represión de la dictadura militar, los miles de desaparecidos y los centros clandestinos de detención.

que los artistas ASCII contemporáneos hacen hincapié en las conexiones entre esta forma artística y una larga historia de experimentación pre-digital y textual; ver, por ejemplo, las referencias que hace Cosic a autores y artistas como Mallarmé, Apollinaire, Dada, y OuLiPo como precursores del arte-ASCII (20).

${ }^{3}$ JODI es el nombre del conjunto artístico formado por Joan Heemskerk y Dirk Paesmans, pioneros del net.art.

${ }^{4}$ Véanse, por ejemplo, el Relational Border Map (2007) o DemoScape . 
De esta manera, la interfaz nos indica varios elementos: el uso resistente de la tecnología; la conexión al pasado; y el enfoque en el lugar físico. Estos tres elementos se ven en todas las obras de la exposición, que presentan una visión crítica de la dictadura militar, un intento de rescatar del olvido la memoria de los desaparecidos, y la representación del entorno físico, en particular las ciudades de Buenos Aires y Bahía Blanca.

Después de esta pantalla con su contenido deliberadamente anacrónico, sale el título de la exposición en la parte inferior de la pantalla, escrito en minúscula: «women and the memory of repression in argentina». Por debajo y por encima de este texto aparecen dos líneas compuestas del símbolo «+»; tanto los símbolos como las letras del título se encuentran en constante movimiento, y flotan hacia arriba y hacia abajo, o cambian de sitio el uno con el otro, de manera desconcertante. A la izquierda del título se distingue un ícono que se repite en varias otras páginas de esta obra: un pañuelo blanco, formado como si tapara una cabeza, pero con un espacio hueco en el lugar de la cara. Este pañuelo es el símbolo de Madres de Plaza de Mayo: llevado por las Madres por primera vez en 1977 cuando se reunieron en la Plaza para protestar en contra de la dictadura, el pañuelo se ha convertido hoy día en el símbolo más reconocido del grupo. Según Guzmán Bouvard, el pañuelo blanco es un «symbol of love and unity» [símbolo de amor y unidad], pero también, como lo explica Hebe de Bonafini, una de las fundadoras de Madres, se sigue usando este símbolo hoy día como una forma de «condemnation of torture, rape, assassination and theft in this country» [protesta contra la tortura, las violaciones, los asesinatos y los robos en este país] (citado en Guzmán Bouvard, 1994: 182). El estilo en que se presenta el pañuelo en la interfaz — con la forma de la cabeza, pero hueco, sin cara — se ha utilizado en varias protestas, e identifica una de las dos facciones de las Madres: la Asociación Madres de Plaza de Mayo, quienes siguen utilizando este símbolo hoy día ${ }^{5}$. En 1986 las Madres de Plaza de Mayo se dividieron en dos facciones: Asociación Madres de Plaza de Mayo y Madres de Plaza de Mayo-Línea Fundadora. Como lo explica Bosco, mientras que la Línea Fundadora mantenía que sus objetivos seguían siendo la búsqueda de la verdad y la justicia en relación con los desaparecidos de la dictadura, la Asociación, en cambio, se perfilaba como un grupo que buscaba el cambio social en un sentido más amplio, y adoptó una postura más revolucionaria, anti-capitalista y anarquista (Bosco, 2004: 388). El hecho de seleccionar este símbolo para la interfaz enfatiza, entonces, que las obras incluidas en la exposición van a tener una postura más radical y anti-capitalista, siguiendo el énfasis de la Asociación.

Luego, después de aparecer el título y el ícono, los demás elementos de la interfaz aparecen en la pantalla. Primero, vemos como fondo una fotografía en blanco y negro de una plaza de la ciudad de Buenos Aires, con árboles en el segundo plano, un grupo de espectadores formando un semicírculo, y, en el primer plano, una pareja en pose de tango clásico. La imagen es genérica: hay poca profundidad de perspectiva, y no se distinguen los edificios del fondo, ni ningún otro punto de referencia. Así, la plaza representa a Buenos Aires en su totalidad, y, por antonomasia, la Plaza de Mayo.

\footnotetext{
5 Este símbolo lo emplea la Asociación en su sitio web, en sus comunicados de prensa, en su cuenta de Twitter, y en su revista, Ni un paso atrás, en la que la «o» de «paso» se remplaza por el símbolo del pañuelo.
} 
Luego, superpuestos encima de este fondo monocromático entran en fundido tres fotografías de color y un archivo de vídeo, cada uno de tamaño distinto. A la izquierda una fotografía grande, de formato paisaje, ocupa un porcentaje considerable de la pantalla, y muestra una manifestación de las Madres de Plaza de Mayo, con un grupo de mujeres captadas en plan americain; con los brazos levantados y la boca abierta, llevan un pañuelo blanco en la cabeza, y portan fotografías de sus hijos desparecidos colgadas alrededor del cuello. En la parte superior derecha de la pantalla, una fotografía más pequeña, en primer plano, muestra una de las Madres; con pañuelo blanco en la cabeza, indica con el dedo hacia la cámara, de manera acusadora. Aunque la imagen no lleva título, la persona es, de modo inconfundible, Hebe de Bonafini, fundadora de la Asociación Madres de Plaza de Mayo y su más prominente portavoz hoy día. Luego, a la extrema derecha de la pantalla aparece una fotografía grande, en formato retrato, mostrando una de las madres protestando. Lleva en la cabeza un pañuelo negro y, colgada alrededor del cuello, una fotografía de tres jóvenes, con la palabra «fusilados» por debajo. Y luego, finalmente, sale en el centro de la pantalla un video en una pantalla pequeña, mostrando una pareja bailando tango en un salón de baile.

La interfaz nos ha presentado entonces una imagen de la ciudad de Buenos Aires que luego se ve desafiada por los múltiples imágenes y enlaces que están superpuestos en la interfaz. La imagen de fondo nos presenta la imagen turística convencional de Buenos Aires: la ciudad en primavera, el «París de las Américas» y el tango como el baile de la pasión. Pero, esta imagen se ve socavada por las imágenes y los enlaces resistentes. El hecho de que las tres fotografías de las Madres se superponen y parcialmente tapan la plaza del fondo indica que, por debajo de la imagen turística de la ciudad, yacen los cuerpos de los desaparecidos. La interfaz, entonces, rechaza la imagen turística de la ciudad y nos indica, a través de las múltiples capas de imágenes y enlaces, que por debajo de esta imagen hay una historia socio-política compleja.

Luego, al navegar esta interfaz, encontramos una variedad de obras que combinan imagen, texto y sonido para crear una memoria resistente de la época de la guerra sucia, y en las que resaltan la historias de las mujeres como madres de desaparecidos, y como víctimas de la represión. Aunque hay una variedad de obras incluidas en la exposición, para dar un ejemplo voy a centrarme en una sección en particular llamada «Testimonios», en donde se re-presentan textos impresos de manera creativa y activa, mediante un proceso de remix o de re-mezclar contenido.

Como ejemplo ilustrativo de este proceso de re-mezclar analizaremos el caso del poema, «The Hordes Came» de Etelvina Astrada. Al seleccionar el enlace se abre una pantalla encima de la pantalla principal, que contiene el poema de Astrada y una imagen. La imagen muestra un grafiti en el que predominan tres colores - blanco, negro y rojo- y representa a tres personajes de uniforme militar, pero en vez de cara, tienen una calavera. A la izquierda de estos personajes, se distingue la bandera argentina, pero su azul celeste está reducido a un gris sucio. El estilo del grafiti toma prestados elementos del Guernica de Picasso (1937), en el uso de ángulos agudos, perspectiva torcida, y poca variedad de colores para representar un escenario de terror. Por debajo de la imagen, el título que lleva 
el grafiti es «Damned Military Junta» [Maldita junta militar], indicándonos que el grafiti es un comentario sobre la dictadura militar.

Pero, además del estilo y del contenido de la imagen, el género también dialoga con la interfaz en la que está incluida. El uso del grafiti como género - a diferencia de, digamos, el óleo, o la escultura - tiene particular importancia en la relación entre el grafiti y el espacio urbano. Porque el grafiti es, como lo han demostrado varios estudios, un género artístico que se pinta en la infraestructura misma de la ciudad, y cuyo estilo y contenido frecuentemente se encuentran en oposición al orden oficial de la ciudad. Los semióticos Scollon y Scollon definen al grafiti como un «transgressive sign» [símbolo transgresivo], dado que este «violates sensibilities and laws of emplacement» [infringe las sensibilidades y las leyes de la organización del espacio] (2003: 146-167). Y en un contexto más específico, las investigaciones que se han llevado a cabo sobre el grafiti en las zonas urbanas en América Latina han demostrado que el arte grafitero se vincula fuertemente con su localidad, y representa un intento de resistir el orden urbano dominante ${ }^{6}$. Esta imagen, entonces, comunica no solo por su estilo y contenido, sino también por su «emplacement»; es una inscripción resistente en la infraestructura urbana que socava la imagen turística de la plaza bonaerense y el tango con la que se abrió la interfaz.

Además, la imagen cobra aún más poder comunicativo cuando se observa en conjunto con el poema que la acompaña, y se establece una dinámica creativa entre texto, imagen e interfaz de fondo. La autora del poema es la poeta argentina Etelvina Astrada, que emigró de Argentina a España en 1974 para escaparse de la represión política después de que el régimen militar secuestrara a su hijo mayor. Astrada publicó dos antologías de poemas, Autobiografía con gatillo (1980) y La muerte arrebatada (1981), además de una antología editada, Poesía política combativa argentina (1978), en la que se puso la tarea de reunir voces críticas de la dictadura argentina. El poema que se reproduce aquí — «The hordes came, in my country»— se publicó en el volumen editado por Alicia Partnoy, You Can 't Drown the Fire: Latin American Women Writing in Exile (1989), antología dedicada a darle la voz a las mujeres en situaciones de represión a través del continente.

«The hordes came» es uno de los poemas más abiertamente políticos de Astrada, e incluye referencias directas a la maquinaria del estado de terror, y el efecto de este en la población. Además, las imágenes poéticas de Astrada dialogan de manera creativa con las imágenes visuales del grafiti. Por ejemplo, los tres personajes del grafiti se asocian con la cuarta estrofa del poema, cuando la voz poética nos habla de los «Three polluted asses/ and a single face truly sinister./ Three professional buzzards». Aquí, la triada en el poema de Astrada se ve reflejada en los tres personajes del grafiti, y

\footnotetext{
${ }^{6}$ Véanse, por ejemplo, el estudio de Da Silva Iddings, McCafferty y Teixeira da Silva sobre el grafiti en el barrio Vila Madalena de São Paulo, en el demuestran que el graffiti es «ecosocial», dado que está «integrated into the environment, semiotically interacting with the space it occupies and the inhabitants» [integrado en el entorno, interactuando semióticamente con el espacio que ocupa y sus residentes] (2011: 13); o el estudio de Kane sobre el grafiti en Buenos Aires, en el que la autora propone que se debe entender el grafiti como un «illegal, multi-vocal, visual urban discourse that alters the texture of street experience through inventive juxtaposition of mass-mediated and local imagery» [discurso urbano ilegal y multi-vocal que cambia la contextura de la experiencia callejera a través de la yuxtaposición con un imaginario mediático y local] (2009: 9).
} 
ambos hacen referencia a los tres líderes de la Junta militar en el momento de tomar el poder: el Teniente General Jorge Rafael Videla, el Comandante en Jefe de la Armada Emilio Massera y el Brigadier General Orlando Ramón Agosti. De igual manera, la metáfora del poema de Astrada de la «single face» se ve complementada en el grafiti, que se niega a darles cara humana a los tres generales. También, la lista de nombres que nos presenta Astrada en la tercera estrofa, y que sirve tanto como manera de llamar la lista de los desaparecidos como de rescatarlos del olvido, encuentra su eco en el grafiti en las imágenes borrosas, apenas visibles, en el primer plano, que parcialmente tapan los pechos de los tres generales y que parecen mostrar imágenes de desaparecidos.

Y el último elemento, y tal vez el más impactante, en este juego de imagen-texto-enlace se encuentra en el fondo: por detrás del poema y del grafiti, todavía se distingue la interfaz de la exposición. Así, mientras leemos el poema y miramos el grafiti, no nos podemos olvidar de la ciudad de Buenos Aires y de la Plaza, que siempre permanecen presentes. De igual manera, el dedo de Hebe de Bonafini todavía se distingue, a través del texto del poema, apuntando, de manera acusadora, hacia el lector mientas lee. De esta manera, las Madres de Plaza de Mayo siempre están presentes mientras leemos, y el juego interfaz-poema nos anima a interpretar al poema como expresión poética de la resistencia a la dictadura militar. Así, la interfaz de la exposición es mucho más que la simple reproducción de un poema en una página web; al contrario, gracias a su juego complejo de yuxtaposición y superposición de elementos, tanto visuales como textuales y sonoros, por las múltiples capas que narran historias resistentes, esta interfaz funciona como obra poética en sí misma.

Si el ejemplo analizado más arriba demuestra la poética de la re-articulación de textos impresos mediante la tecnología digital, el ejemplo que analizaremos a continuación representa una poética construida directamente desde las tecnologías digitales. Este es el caso de la obra de la escritora argentina-española, Belén Gache, quien hasta la fecha ha publicado varias obras que utilizan formatos digitales, como poemas digitales, manifiestos-robot y diarios-blog. En su reciente obra, Radical karaoke (2011), Gache crea una serie de poesías que re-mezclan frases hechas y lugares comunes y que, al mismo tiempo, permiten al lector-usuario crear mezclas de voz, sonido, imagen y efectos especiales.

Gache describe a Radikal Karaoke como un «conjunto de poesías que se apropian de la retórica de la propaganda política» y que intenta «interrogar los discursos hegemónicos y trabaja con el permanente contraste entre la utopía y el lugar común». Como veremos a continuación, la forma en que se construyen estas poesías, y la manera en que el lector-usuario las va activando, nos animan a desconstruir los discursos hegemónicos por medio de la parodia.

Radical Karaoke consiste en una obra en línea mediante el cual el lector-usuario puede pronunciar poemas en formato de discursos políticos, y activar una variedad de efectos especiales. La página de entrada de Radikal Karaoke se sirve de un rango limitado de colores en el que predominan el azul, el verde y el negro. A la izquierda de la pantalla se distingue la silueta de un hombre con micrófono en mano, al estilo clásico del karaoke; a la derecha de la pantalla, está el título de la obra, $\mathrm{y}$, por encima de este, la sigla «RK» dentro de un círculo, con la «R» al revés. Por detrás, como telón 
de fondo y cubriendo toda la pantalla, se devisa un mapa borroso, de azul oscuro. Luego, entre la imagen y el título en el primer plano, y el mapa en el fondo, en el plano mediano se distingue una fila de personajes, también siluetados, todos con traje y corbata.

Ya antes de entrar en la obra en sí, percibimos cómo Gache nos indica las preocupaciones principales de su obra. El hecho de representar el título de la obra por una sigla, y dentro de un círculo, recuerda inmediatamente a la sigla «TM»o «marca comercial», y nos remite a poderes corporativos. Asimismo, la imagen del fondo - un mapa del mundo - nos hace cuestionar a qué extremos pueden llegan estos poderes corporativos. Igualmente, la fila de personajes de traje y corbata, cuyas siluetas borrosas apenas se distinguen, y cuyos rostros no son visibles, nos hace pensar en los poderes anónimos de las grandes corporaciones.

Luego, al seleccionar «entrar» para activar la obra, se abre primero una pantalla negra con un texto corto en letra de neón rojo — «loading» [cargando]— y luego la interfaz principal de la obra. Después de seleccionar el idioma — son dos las opciones, español o inglés - se carga una pantalla verde en la que se nos ofrecen tres posibles discursos. Mediante un botón, escogemos entre «Ex Africa semper aliquid novi», «Mirad como Kate presume de su anillo»y «We have no past, you have no present». El primero parte de un aforismo recopilado en la Historia Naturalis del escritor romano Plinio el Viejo (AD 23-79), en que Plinio recuenta un aforismo griego, traduciéndolo al latín ${ }^{7}$. Esta frase, que comunica la idea de que «África siempre nos trae algo novedoso», se ha vuelto un lugar común, y ha sido empleada con frecuencia en nuestros días para acompañar informes, películas y documentales sobre el continente.

El segundo discurso, en cambio, tiene sus orígenes en un momento híper-contemporáneo: se refiere a la entonces novia del príncipe William del Reino Unido, Kate Middleton, y el momento en que mostró su anillo de compromiso a la prensa. El título de este discurso, entonces, hace referencia al llamado «Kate Middleton-mania», y a las vaciedades de la prensa moderna, en su continuo afán de comentar los pormenores de la vida de las familias reales. El tercer discurso tiene orígenes mezclados, pero recuerda sobre todo el eslogan punquero «no future», de la canción nihilista «God Save the Queen» de los Sex Pistols.

Al seleccionar uno de estos tres discursos, se abre la interfaz interactiva de la obra. La parte principal de la pantalla la ocupa un vídeo en blanco y negro que muestra varias filas de espectadores, aplaudiendo. El vídeo está en circuito continuo y acelerado, de modo que los espectadores siguen aplaudiendo sin descanso, y mueven las manos en un ritmo frenético mientras miran hacia nosotros. Por debajo de este vídeo se encuentra el tablero de control de la obra: primero, vemos catorce botones con letras por debajo y, por debajo de éstas, el texto del karaoke.

En esta obra, más que en $W: M o R$, el usuario tiene que tomar un papel activo en ejecutar la poesía. Primero, nuestra participación activa se requiere para la lectura en voz alta del texto, ya que, al estilo

\footnotetext{
${ }^{7}$ Aunque popularmente se atribuye la frase a Plinio, él mismo reconoce que está recopilando un aforismo griego, y Feinberg y Solodow (2002) demuestran que tiene sus orígenes en la obra de Aristóteles, quien, a su vez, estaba comentando un refrán popular.
} 
karaoke, las palabras del poema aparecen en la parte inferior del tablero de control, para que el lectorusuario las vocalice. Utilizando las flechas del tablero, el lector-usuario hace avanzar el texto, y debe vociferar una serie de lugares comunes. Por ejemplo, al seleccionar un discurso, leemos el siguiente texto: «Buenas tardes. Es un honor estar hoy aquí frente a esta audiencia. Aprovechare esta ocasión para deciros...».

Las palabras en este extracto se reproducen al comienzo de los dos primeros discursos. Y, si miramos con atención, el texto que vemos $-\mathrm{y}$, si seguimos las reglas de este juego poético, el que vocalizamos - se forma de una serie de lugares comunes, exentos de originalidad. Las frases de bienvenida — «buenas tardes»; «hoy aquí»; «esta audiencia»; «esta ocasión»— no tienen contexto fijo y sirven para cualquier propósito. El discurso que leemos, entonces, con toda su retórica, carece de originalidad y de sinceridad. Así, Gache nos revela las vaciedades del discurso político, ya que las mismas frases se repiten ad nauseum, y resultamos repitiendo los mismos lugares comunes.

Después de las frases de bienvenida, las que siguen se forman de una combinación de los textos encontrados. Como lo explica Gache, los poemas están construidos «a partir de una estructura verbal fija y textos aleatorios», y así, el valor poético de esta obra no se encuentra en la originalidad de cada frase en sí, sino en la combinación creativa, y a veces chocante, de estas frases. Esta técnica poética - la combinación creativa de fragmentos de texto - se hace posible mediante la tecnología digital, pero, al mismo tiempo, toma elementos prestados de una larga tradición literaria. Precursores notables de la táctica de Gache se encuentran en las obras del taller OuLiPo, en las múltiples variaciones poéticas basadas en la recombinación de frases al estilo Raymond Queneau y su Cent mille milliards de poèmes (1961), en los juegos de los surrealistas - influencia que ha mencionado Gache muchas veces en sus escritos y entrevistas - para nombrar solo algunos ejemplos. En cuanto a lo que es la parte puramente textual de esta obra, entonces, Gache utiliza la tecnología moderna para generar poesías, pero basándose en la tradición literaria.

Si la vocalización del texto es el primer grado de interactividad que se requiere del lector en esta obra, un segundo grado de interactividad, más profundo y activo, se encuentra en la parte visual de la obra. Porque es el lector-usuario quien ejecuta la poética visual de la obra. Los efectos visuales los controla el lector-usuario mediante las teclas indicadas en el tablero de control, y, al teclear la letra indicada, se producen cambios en la pantalla central de la obra. Las siete teclas indicadas a mano derecha - Z, R, G, B, K, A1 y A2- producen modificaciones en el video de la pantalla principal, cambiándolo de color o de velocidad. Así, por ejemplo, al presionar una tecla la imagen del video se tiñe de verde, o de amarillo, según la tecla que escogemos.

Si tal es el efecto de las siete teclas a mano derecha, las siete teclas a mano izquierda (V1-7) cambian el video por completo y lo remplazan por otra imagen. Mediante estos controles, podemos remplazar la imagen original (los espectadores que nos aplauden) por: una bomba nuclear que se estalla (V2); una espiral alucinante (V3); una cara amenazante con ojos rojos e hipnotizados en forma de espiral (V4); un extra-terrestre que se desplaza rápidamente frente a un escenario urbano (V5); unos esclavos arrastrando un bulto descomunal (V6). A igual que el vídeo original, todos estos vídeos se 
repiten en circuito continuo y, en su contenido, nos hacen reflexionar sobre las palabras que estamos contemplando. Los vídeos funcionan como un comentario meta-poético, que nos hace cuestionar el texto que corre en la parte inferior de la pantalla y el que, si seguimos las reglas del juego, debemos pronunciar en voz alta.

Por ejemplo, si seleccionamos V6, la imagen de los esclavos arrastrando su bulto nos ofrece una visión pesimista de la vida del siglo veintiuno. Dado que el vídeo está presentado en circuito continuo —en realidad, el vídeo dura escasamente unos 3 minutos, y vuelve a empezar-, los esclavos avanzan unos pocos centímetros, haciendo un gran esfuerzo, para luego volver al mismo sitio y empezar todo de nuevo. Al igual que el Sísifo mítico, condenado a repetir la misma tarea hasta la eternidad (y que el escritor francés Albert Camus ya nos había ofrecido como metáfora del ser humano moderno del siglo XX), el vídeo de Gache nos ofrece nuestra propia imagen, como seres atrapados en un continuo ciclo sin descanso, esclavizados por las grandes corporaciones y el capitalismo tardío del siglo veintiuno.

Asimismo, si seleccionamos V4, la imagen nos refleja nuestro estatus contemporáneo. En esta imagen resaltan los ojos hipnotizados, desorbitados, en los que la pupila se ha remplazado por un vertiginoso espiral, en constante movimiento. Estos, junto con el tono de rojo oscuro que tiñe la imagen en su totalidad, producen un efecto desconcertante, en el que la cara humana se ve distorsionada y angustiada. Así, este vídeo nos refleja nuestra situación contemporánea: hipnotizado por el consumismo, y, por qué no, hipnotizado por las tecnologías digitales, el ser humano se ve convertido en zombi. Esta es una táctica frecuente en las obras de Gache: lejos de presentarnos una visión utópica de un mundo digital avanzado, Gache siempre nos hace cuestionar la misma tecnología digital en la que se basa su obra, y nos sugiere los peligros de dejarnos hipnotizar por las redes digitales.

En todos estos ejemplos, Gache nos anima a deconstruir los textos que estamos pronunciando. Por ejemplo, si seleccionamos V6 observaremos un contraste marcado entre la retórica que pronunciamos, al llegar a la frase «nosotros somos los protagonistas» y la imagen de los esclavos, en la que, forzosamente, estamos lejos de protagonizar la historia. Así, mientras leemos el texto y manipulamos las imágenes, percibimos que el blanco de la crítica de Gache es el neoliberalismo y los grandes poderes corporativos, la retórica política, y el consumo indiscriminado de las redes digitales.

Si tal es el efecto al seleccionar las teclas V1 al V6, cuando creamos poesía en la mezcla de texto e imagen, es el último de estos videos, el V7, que resulta ser el más chocante y preocupante para el lector-usuario. Porque, después de pasar por esa fila de esclavos, de extra-terrestres, y de entes cibernéticos, si activamos la tecla V7, lo que se carga en la pantalla principal es la imagen de nuestra propia webcam. Es decir, $R K$ capta la imagen de nuestra webcam y la proyecta en la pantalla delante de nosotros; lo que vemos en la pantalla es nuestro propio rostro, frente a la computadora, mientras leemos el poema. Así, el usuario se encuentra implicado en la obra: lo que nos indica Gache con este truco desconcertante es que nosotros también somos clones, hipnotizados por y atrapados en el sistema, igual que los personajes que vimos en los vídeos anteriores.

Lo que hemos visto en estas dos obras, entonces, es una variedad de tácticas y estilos, pero al mismo tiempo unas preocupaciones compartidas. En el primer ejemplo, la obra colaborativa de 
Agrícola de Cologne y Partnoy, vemos cómo los autores se aprovechan de los medios digitales para re-activar y re-mezclar poesía, prosa, imagen y sonido. En el segundo, la obra de Gache, vemos la utilización de algoritmos y re-combinaciones en la producción de la poesía en sí. Si bien el primero está mucho más relacionado con el contorno socio-político argentino en concreto, el segundo, no obstante, comparte con el primero el mismo deseo de desenmascarar los discursos hegemónicos del poder. Si para Agrícola de Cologne y Partnoy los discursos del poder eran los de la dictadura militar, para Gache son los poderes cuasi ilimitados de las grandes corporaciones que deberían ser cuestionados.

\section{Bibliografía}

Agricola de Cologne, Wilfried - Partnoy, Raquel (2003): Women: Memory of Repression in Argentina, en https://rhizome.org/art/artbase/artwork/women-memory-of-repression-in-argentina/ (última consulta, 1-3-2013).

ASTRADA, Etelvina, ed. (1978): Poesía política y combativa argentina. Guernica, Zero.

— (1980): Autobiografía con gatillo. Madrid, Ayuso.

(1981): Muerte arrebatada. Barcelona, Ámbito Literario.

- (1984): Autobiography at the Trigger. Trad. Timothy J. Rogers. York, Spanish Literature Publications Co.

BosCO, Fernando J. (2004): «Human Rights Politics and Scaled Performances of Memory: Conflicts among the Madres de Plaza de Mayo in Argentina», Social \& Cultural Geography, 5/3, pp. 381402.

Da Silva Iddings, Ana Christina - McCAFferty, Steven G. - TeIXEIRA DA Silva, Maria Lucia (2011): «Conscientização through Graffiti Literacies in the Streets of a São Paulo Neighborhood: An Ecosocial Semiotic Perspective», Reading Research Quarterly, 46/1, pp. 5-21.

FEINBERG, Harvey M. - Solodow, Joseph B (2002): «Out of Africa», The Journal of African History, 43/2, pp. 255-261.

Fusco, Coco - DomíngueZ, Ricardo (2005): Turista Fronterizo, en http://www.thing.net/ cocofusco/ StartPage.html (última consulta, 1-3-2013).

GACHE, Belén (2011) Radikal Karaoke, en http://belengache.net (última consulta, 1-7-2016)

GUZIK GLANTZ, Noemi (2005-): http://noemi.guzikglantz.com/ (última consulta, 7-7-2016).

GuZMÁN Bouvard, Marguerite (1994): Revolutionizing Motherhood: The Mothers of the Plaza de Mayo. Wilmington, Scholarly Resources.

KANE, Stephanie (2009): «Stencil Graffiti in Urban Waterscapes of Buenos Aires and Rosario, Argentina», Crime, Media Culture, 5/9, pp. 9-28.

LiU, Alan (2004): The Laws of Cool: Knowledge Work and the Culture of Information. Chicago, University of Chicago Press.

MACKERN, Brian (2000-2005): Netart latino database, en http://netart.org.uy/latino/ (última consulta, 1-7-2016). 
90 | Tropelías. Revista de Teoría de la Literatura y Literatura Comparada, 27 (2017) Claire Taylor

NiÑo, Martha Patricia (2005): Demo Scape V 0.5., en http://www.martha-patricia.net (última consulta, 1-7-2012).

(2007a): Relational Border Map, en http://www.martha-patricia.net/relational-bordermap.html (última consulta, 1-7-2012).

PARTNOY, Alicia, ed. (1989): You Can't Drown the Fire: Latin American Women Writing in Exile. Londres, Virago.

Queneau, Raymond (1961): Cent mille milliards de poèmes. París, Gallimard.

Scollon, Ron y Scollon, Suzie Wong (2003): Discourses in Place: Language in the Material World. Nueva York, Routledge.

TAYLOR, Claire (2007): «Virtual Bodies in Cyberspace: Guzik Glantz's Weblog», en Claire TAYLOR y Thea PITMAn, eds., Latin American Cyberculture and Cyberliterature. Liverpool, LUP, pp. 244-256.

(2016) «Twitter-poesía y aforismos re-mezclados: Poemita y Minima Moralia Redux de Eduardo Navas», en Luis CorreA-Díaz y Scott WeInTRAub, eds., Poesía y poéticas digitales/electrónicas/tecnos/New-Media en América Latina: Definiciones y exploraciones. Bogotá, Universidad Central, pp. 201-221. 